\title{
Relative importance of slope material properties and timing of rainfall for the occurrence of landslides
}

\author{
Daizo TSUTSUMI $^{1}$ and Masaharu FUJITA ${ }^{2}$ \\ ${ }^{1}$ Disaster Prevention Research Institute, Kyoto University (436-13 Nakao, Okuhidaonsengo, Takayama, Gifu 506-1422, Japan) \\ 2 Disaster Prevention Research Institute, Kyoto University (Higashinokuchi, Shimomisu, \\ Fushimi-ku, Kyoto, Kyoto 612-8235, Japan)
}

\begin{abstract}
Throughout Japan, almost all areas near hillsides or mountain slopes are threatened by landslides caused by heavy rainfall during the rainy and typhoon seasons. To mitigate potential disasters, many researchers have investigated landslides caused by heavy rainfall and have developed simulation models to predict landslide occurrence. However, because landslide mechanisms are complicated and involve many factors such as rainfall, surface and subsurface geomorphology, and soil physical properties, accurate prediction of landslides remains difficult by conventional simulation methods. Over the last several decades, many researchers have reported the existence of numerous preferential flow pathways for subsurface runoff, such as soil pipes or macro-pores in the soil layer. Simple infiltration analysis ignores those preferential flow pathways and therefore does not accurately simulate actual soil water flow, making it difficult to predict landslide occurrence accurately. For the last five years, we have investigated several landslide sites and have used experimental and modeling approaches to examine landslide occurrence. The results confirm that to improve precision of landslide prediction, simulation models should incorporate some important factors that affect landslide occurrence. This paper reports these issues as well as the results of the landslide investigations, and discusses the methods required to predict and mitigate landslide disasters.
\end{abstract}

\section{INTRODUCTION}

Landslides triggered by heavy rainfall are natural processes and are affected by various factors such as rainfall characteristics, soil strength and hydraulic properties, and subsurface geomorphology. Researchers have long investigated the relationships between landslides and these conditioning factors. Rainfall is the most important factor, and the relationship between rainfall characteristics and landslides has been studied intensively [e.g., Iverson, 2000; Keefer et al., 1987; Sidle and Swanston, 1981]. Soil hydraulic properties control rainfall infiltration within the soil layer, and soil strength refers to soil resistance against the sliding force of soil mass. Considerable research has also been conducted on these important soil physical properties [e.g., Harp et al., 1990; Montgomery, 1997; Vieira and Fernandes, 2004]. Subsurface geomorphology, including preferential flow pathways and concave bedrock topography, concentrates infiltrated rainwater and is thought to be closely related to landslide occurrence. Therefore, researchers have also widely studied subsurface geomorphology [e.g., Dietrich and Dunne, 1978; Hack and Goodlett, 1960; Uchida et al., 2001]. The importance of these conditioning factors is now well understood, and the mechanisms by which they affect landslides have been widely investigated. However, methods incorporating these factors to predict landslides triggered by heavy rainfall are insufficiently developed. Generally, model simulations are effective methods for confirming and clarifying the mechanisms of a physical process including various conditioning factors. Therefore, simulations of landslides, incorporating the effects of factors such as rainfall characteristics, soil physical properties, and subsurface geomorphology, can elucidate the mechanisms. Development of a simulation method that incorporates detailed landslide mechanisms is an essential component for accurately predicting landslide occurrence and mitigating sediment-related disasters.

Over the last five years, frequent landslide disasters have occurred throughout Japan. We visited several landslide sites (see Table 1) and examined each in regard to the geomorphology of the landslide scar, bedrock topography, soil hydraulic properties, and the rainfall condition antecedent to the landslide.

Information about the landslides was also collected from residents who had witnessed the events. All of the information was synthesized and confirmed that several factors are vital to clarifying the mechanism of landslide occurrence:

1) preferential flow pathways within the subsurface layer; 
2) multi-phase slope failure;

3) soil physical properties, including hydraulic properties and soil strength; and

4) rainfall characteristics.

This study used a physical experiment and numerical simulations combining rainwater infiltration analysis and slope stability analysis to clarify the mechanisms by which these factors contribute to the occurrence of landslides.

The following sections will present the methods used by the model to simulate rainwater infiltration and slope stability, along with a detailed discussion of each factor including observations at the actual landslide sites, physical experiments, and numerical simulations.

\section{SIMULATION METHOD}

\subsection{Rainwater infiltration analysis}

Water flow within a soil matrix can be calculated using Richard's equation:

$$
C(\psi) \frac{\partial \psi}{\partial t}=\nabla \cdot[K(\psi) \nabla(\psi+z)]
$$

where $C(\psi)$ is the soil water capacity and $K(\psi)$ is the hydraulic conductivity. The lognormal model proposed by Kosugi [1996] can be used to represent $C(\psi)$ and $K(\psi)$ for unsaturated conditions $(\psi<0)$ :

$$
\begin{aligned}
& C(\psi)=\frac{\theta_{s}-\theta_{r}}{\sqrt{2 \pi} \sigma(-\psi)} \exp \left\{-\frac{\left[\ln \left(\psi / \psi_{m}\right)\right]^{2}}{2 \sigma^{2}}\right\} \\
& K(\psi)=K_{s}\left[Q\left(\frac{\ln \left(\psi / \psi_{m}\right)}{\sigma}\right)\right]^{1 / 2}\left[Q\left(\frac{\ln \left(\psi / \psi_{m}\right)}{\sigma}+\sigma\right)\right]^{2}
\end{aligned}
$$

where $\theta_{s}\left[\mathrm{~m}^{3} / \mathrm{m}^{3}\right]$ is the saturated soil water content, $\theta_{r}\left[\mathrm{~m}^{3} / \mathrm{m}^{3}\right]$ is the residual soil water content, $\psi_{m}[\mathrm{~m}]$ is the pressure potential corresponding to the median soil pore radius, $\sigma$ is a dimensionless parameter related to the width of the pore-size distribution, and $K_{s}[\mathrm{~m} / \mathrm{s}]$ is the saturated hydraulic conductivity. The function $Q(x)$ represents the residual normal distribution and can be expressed as

$$
Q(x)=\int_{x}^{\infty} \frac{1}{\sqrt{2 \pi}} \exp \left(-\frac{u^{2}}{2}\right) d u
$$

For saturated conditions $(\psi \geq 0)$, values are set at, $K(\psi)=K_{s}$ and $C(\psi)=0.0$.

Richard's equation can be solved using the finite element method [Istok, 1989; Zienkiewicz, 1971]. In the soil matrix flow calculation, a preferential flow pathway is assumed as a line without volume.

\subsection{Preferential flow model}

Using the preferential flow model developed by Tsutsumi et al. [2005a], the pipeflow was calculated
Table 1 Landslide locations and characteristics

\begin{tabular}{cll}
\hline $\begin{array}{c}\text { Date of } \\
\text { Occurrence }\end{array}$ & \multicolumn{1}{c}{ Location } & \multicolumn{1}{c}{ Remarks } \\
\hline $20 / 07 / 2003$ & $\begin{array}{l}\text { Minamata, } \\
\text { Kumamoto Pref. }\end{array}$ & $\begin{array}{l}\text { Localized } \\
\text { rainstorm }\end{array}$ \\
$01 / 08 / 2004$ & $\begin{array}{l}\text { Kisawa, } \\
\text { Tokushima Pref. }\end{array}$ & Typhoon 0410 \\
& Miyagawa, Mie & \\
29/09/2004 & Typhoon 0421 \\
& Pref. & \\
$06 / 09 / 2005$ & Taketa, Oita & \\
& Pref. & Typhoon 0514 \\
\hline
\end{tabular}

for three differing types of flow within the pipe: (I) no pipeflow, (II) partially filled pipeflow, and (III) full pipeflow. To compute the pipeflow numerically, the pipe was divided into $n_{p}$ segments. The ends of the segments correspond to the nodes used for finite element calculation of the soil matrix flow. Calculation methods for each type of pipeflow are explained below.

\subsubsection{No pipeflow}

In this case, it is not necessary to consider the interaction between pipeflow and soil matrix flow because no water flows within the pipe. The soil matrix flow is calculated as if there were no pipe within the matrix.

\subsubsection{Partially filled pipeflow}

Seepage from the soil matrix into the pipe can be calculated by imposing the Dirichlet boundary condition to the pipe boundary. The pipeflow rate can be computed by summing the seepage from the upper point where pipeflow appears, using the following equation:

$$
Q_{p, k}=\sum_{i=1}^{k} S_{p, i}
$$

where $Q_{p, k}$ is the flow rate within the $k^{\text {th }}$ segment, and $S_{p, i}$ is the seepage (or backflow) at the node corresponding to the upper end of the $i^{\text {th }}$ segment.

\subsubsection{Full pipeflow}

Full pipeflow can be calculated using Manning's equation, based on the experimental results of Kitahara [1989]. The flow rate within the pipe, $Q_{p, k}$, can be expressed as

$$
Q_{p, k}=\frac{1}{n} R^{2 / 3}\left(\frac{\phi_{p, k+1}-\phi_{p, k}}{l_{p, k}}\right)^{1 / 2} A
$$

where $n$ is the roughness coefficient, $R$ is the hydraulic radius, $\phi_{p, k}$ is the hydraulic potential at the lower end of the $k^{t h}$ segment, $l_{p, k}$ is the length of the $k^{\text {th }}$ 
segment, and $A$ is the cross-sectional area of the pipe. Various field pipe configurations can be simulated simply by modifying the cross-sectional area $A$ and the hydraulic radius $R$.

Flux $S_{p, k}$ at a node, which is the junction of pipe segment $k$, can be specified as

$$
S_{p, k}=Q_{p, k}-Q_{p, k-1}
$$

$S_{p, k}$ is then applied to the node as a point source or sink in the soil matrix flow calculation, as shown in the previous subsection.

Soil matrix flow and pipeflow are calculated alternately until the calculated water flows, within the soil matrix and soil pipes, reach convergent stages.

\subsection{Slope stability analysis}

A slope stability analysis was conducted simultaneously with the infiltration analysis. A simplified Janbu method was used to analyze slope stability because this method can be applied to any shape of slip surface. In the simplified Janbu method, a soil layer is divided into vertical slices, and the balance of stresses and slip condition within each slice is assessed. This method is used to calculate the factor of safety $F_{s}$, which can be expressed as

$$
F_{s}=\frac{\sum\left[\left\{c_{i}{ }^{\prime} l_{i} \cos a_{i}+\left(W_{i}-u_{i} l_{i} \cos a_{i}\right) \tan \phi_{i}{ }^{\prime}\right\} / m_{a}\right]}{\sum W_{i} \tan a_{i}}
$$

$$
m_{a}=\cos ^{2} a_{i}\left(1+\tan a_{i} \tan \phi_{i}{ }^{\prime} / F_{s}\right)
$$

where subscript $i$ indicates the number of vertical slices of soil layer, $c_{i}$ ' and $\phi_{i}^{\prime}$ represent the cohesion and internal friction angle of the soil, $W_{i}$ is the weight of the slice, $a_{i}$ and $l_{i}$ represent the angle and length of the slip surface of the slice, and $u_{i}$ is the water pressure affected on the slip surface.

Based on previous studies by Kubota and Nakamura [1991] and Yamagami and Ueta [1988], the dynamic programming (DP) method was used to determine the slip surface that provides a minimum factor of safety. The spatial distribution of pore water pressure, calculated through a rainwater infiltration analysis, was used as input data in the slope stability analysis.

\section{CONSIDERATION OF PREFERENTIAL FLOW PATHWAYS WITHIN A SUBSURFACE LAYER}

Preferential flow pathways within a soil layer generally hasten rainwater infiltration and make a slope more stable. However, researchers have consistently shown that the clogging of preferential flow pathways decreases slope stability and may trigger landslides [e.g., Pierson, 1983: Uchida et al.,

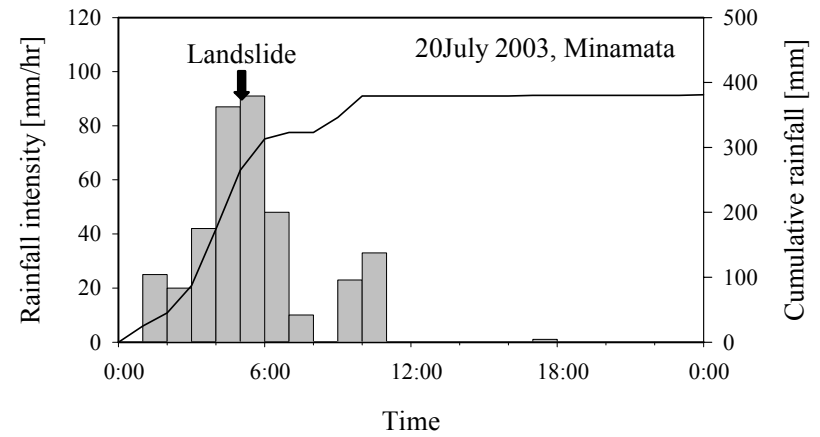

Fig. 1 Observed rainfall on the day of the Minamata landslide (20 July 2003).

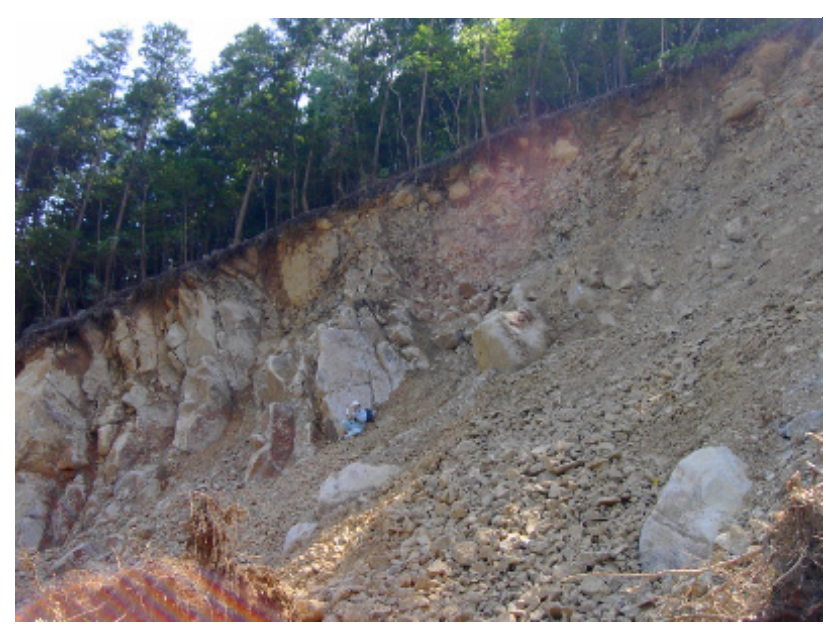

Fig. 2 Fractures within the weathered andesite at the Minamata landslide site (26 July 2003).

1995]. Other studies have confirmed the effects of preferential flow within a soil layer on rainwater infiltration and slope stability using experimental data [Tsutsumi et al., 2005b] and numerical simulations [Tsutsumi et al., 2005c].

Preferential flow through fractures in bedrock has a similar function to that in a soil layer. One example is the landslide that occurred in Minamata, Kumamoto Prefecture, on 20 July 2003. Figure 1 presents the hyetograph for that date. While the area experienced only $70 \mathrm{~mm}$ of rainfall during the 10 days preceding the disaster, a moderately deep landslide (maximum depth of 10-15 m) occurred during the highest rainfall intensity (around 5 a.m., about $90 \mathrm{~mm} / \mathrm{hr}$ ). Observations of the landslide site revealed many fractures in the weathered andesite layer on the tuff-breccia bedrock (Fig. 2). In this situation, it is probable that rapid rainwater transportation through the fractures in the weathered andesite quickly produced pore water pressure at the bottom of the weathered andesite layer, causing the relatively deep-seated landslide without any delay after the time of peak rainfall [Sidle and Chigira, 2004]. 


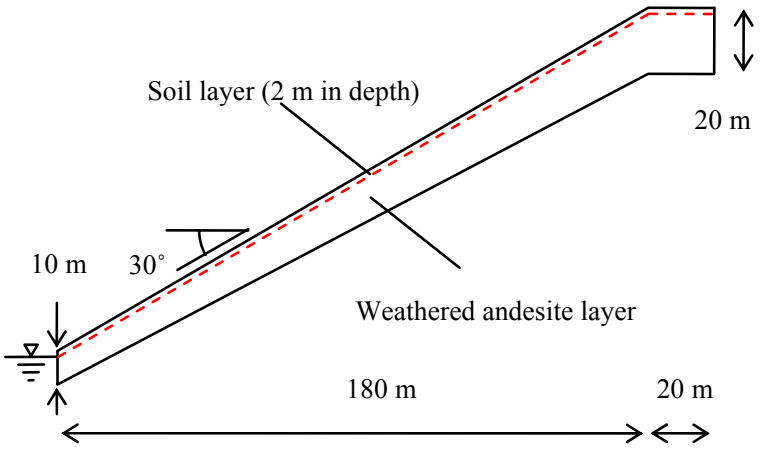

Fig. 3 Assumed problem domain for the numerical simulation, based on the actual geomorphology at the landslide site.

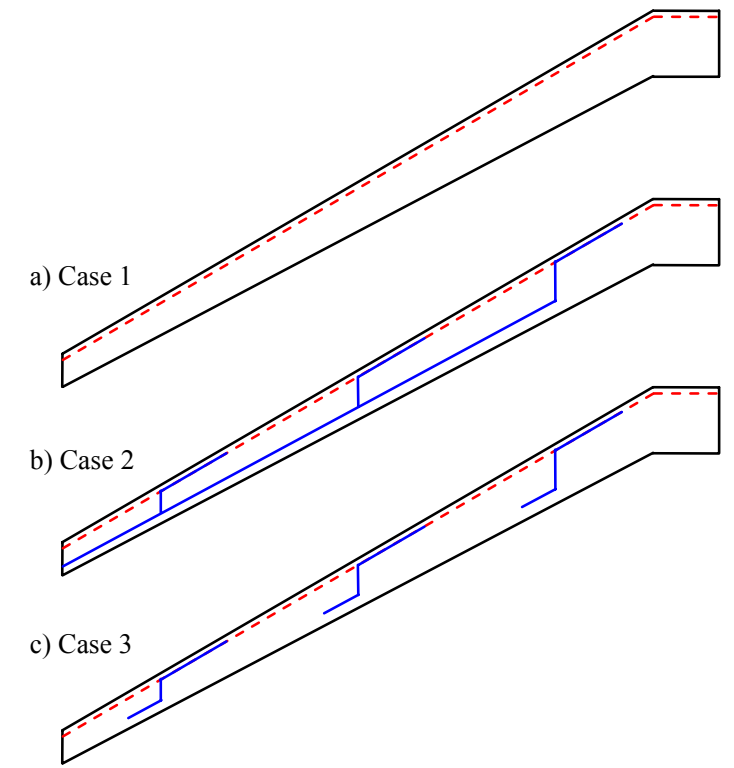

Fig. 4 Three differing cases of preferential flow pathways for numerical simulation (Case 1: no pathways; Case 2: pathways connected to each other and opening at the downslope end; and Case 3: pathways disconnected from each other, and outlets remain within the andesite layer).

To confirm this scenario, numerical simulations were conducted to assess rainwater infiltration and subsequent changes in slope stability. Figure 3 shows the assumed problem domain based on the actual geomorphology at the landslide site. The soil layer was assumed to have a depth of $2 \mathrm{~m}$ from the surface, with the weathered andesite layer below. A no-flux boundary condition was imposed for the bottom of the weathered andesite layer. Calculations included three cases of preferential flow pathways (Cases 1, 2, and 3). Case 1 was based on the assumption of no preferential flow pathway, which was just a simple matrix flow calculation (Fig. 4b). For Case 2, three longitudinal soil pipes with a diameter (d) of $5.0 \mathrm{~cm}$ were placed at a boundary between the soil and weathered andesite layers; these
Table 2 Parameters used in numerical simulation of Minamata landslide

\begin{tabular}{ccc} 
& \multicolumn{2}{c}{ Minamata landslide } \\
& $\begin{array}{c}\text { Surface soil layer } \\
\text { (Sandy soil) }\end{array}$ & $\begin{array}{c}\text { Weathered } \\
\text { andesite layer }\end{array}$ \\
\hline & $K_{s}=0.005 \mathrm{~cm} / \mathrm{s}$ & $K_{s}=0.0001 \mathrm{~cm} / \mathrm{s}$ \\
Hydraulic & $\theta_{r}=0.162 \mathrm{~m}^{3} / \mathrm{m}^{3}$ & $\theta_{r}=0.162 \mathrm{~m}^{3} / \mathrm{m}^{3}$ \\
properties & $\theta_{s}=0.578 \mathrm{~m}^{3} / \mathrm{m}^{3}$ & $\theta_{s}=0.434 \mathrm{~m}^{3} / \mathrm{m}^{3}$ \\
(assumed) & $\psi_{m}=-86.2 \mathrm{cmH}_{2} \mathrm{O}$ & $\psi_{m}=-86.2 \mathrm{cmH}_{2} \mathrm{O}$ \\
& $\sigma=0.639$ & $\sigma=0.639$ \\
\hline
\end{tabular}

P. F.

pathways Diameter $=0.05 \mathrm{~m} \quad$ Diameter $=0.05 \mathrm{~m}$

(assumed)

\begin{tabular}{cll} 
Soil & $c=0.01 \mathrm{tf} / \mathrm{m}^{2}$ & $c=0.0025 \mathrm{tf} / \mathrm{m}^{2}$ \\
strength & $\phi=32.5$ degree & $\phi=35$ degree \\
(assumed) & & \\
\hline
\end{tabular}

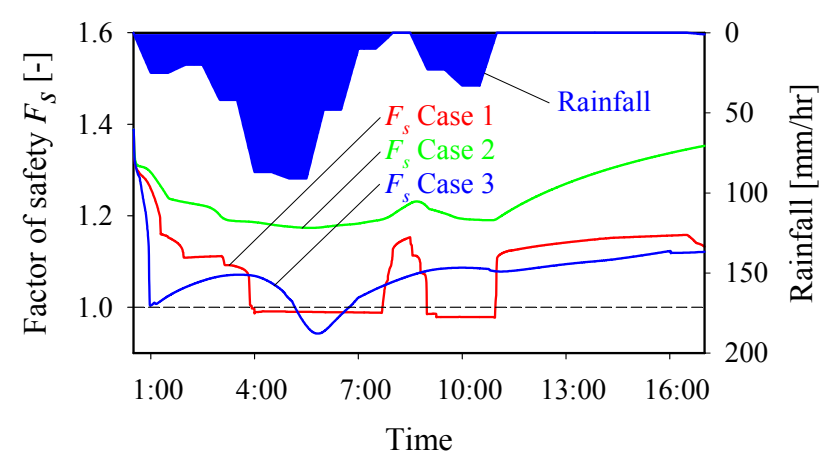

Fig. 5 Calculated changes in the factor of safety for each case, with hyetograph for the simulations

pipes were connected to vertical fractures, the shape of which was similar to that of soil pipes. The vertical fractures were connected to a longitudinal fracture parallel to the slope near the bottom of the weathered andesite layer; this fracture was also similar in shape to a soil pipe. The outlet of the longitudinal fracture parallel to the slope was the opening to the outside of the slope at the downslope end (Fig. 4b). Case 3 was based on preferential flow pathways similar to those used for Case 2, but the longitudinal fracture near the bottom of the weathered andesite layer was discontinuously broken into three longitudinal fractures, and the downstream ends of these longitudinal fractures were located inside the weathered andesite layer (Fig. 4c). All preferential flow pathways were set on a vertical plane across the center of the slope width $(2.0 \mathrm{~m})$. Table 2 lists the hydraulic properties, diameter of assumed 


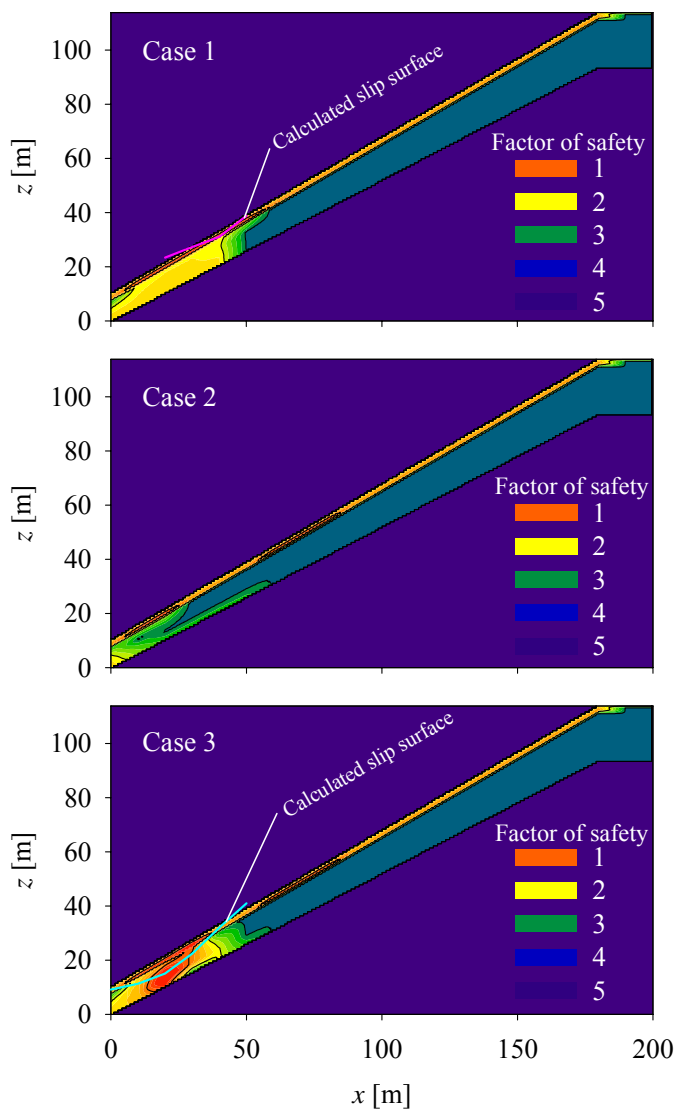

Fig. 6 Distribution of locally calculated factors of safety and critical slip surfaces.

preferential flow pathways, and soil strength for all numerical simulations.

Figure 5 shows calculated changes in the factor of safety for each case, with the hyetograph for the simulations. In Case 1, the factor of safety decreased to below 1.0 at the beginning of the rainfall peak (at 3:55 a.m.). In Case 2, the factor of safety maintained a high level and did not decrease below 1.0. In Case 3 , the factor of safety decreased suddenly at the beginning of rainfall and decreased below 1.0 at the end of the rainfall peak (at 5:10 a.m.). Figure 6 shows the locally calculated distribution of the factor of safety (assuming that the gradient of the slip surface was equal to that of the slope surface) and the calculated slip surfaces when the factor of safety was 1.0. In Case 1, only the surface soil layer collapsed, and no unstable zone appeared within the andesite layer. In Case 3, the slip surface was calculated to cut the unstable zone within the andesite layer, and a relatively deep landslide was simulated. In Case 2, an unstable zone was not calculated due to the drainage effect from the preferential flow pathway. The actual preferential flow network consisting of fractures and soil pipes at the Minamata landslide site was very complex. Therefore, it was not investigated

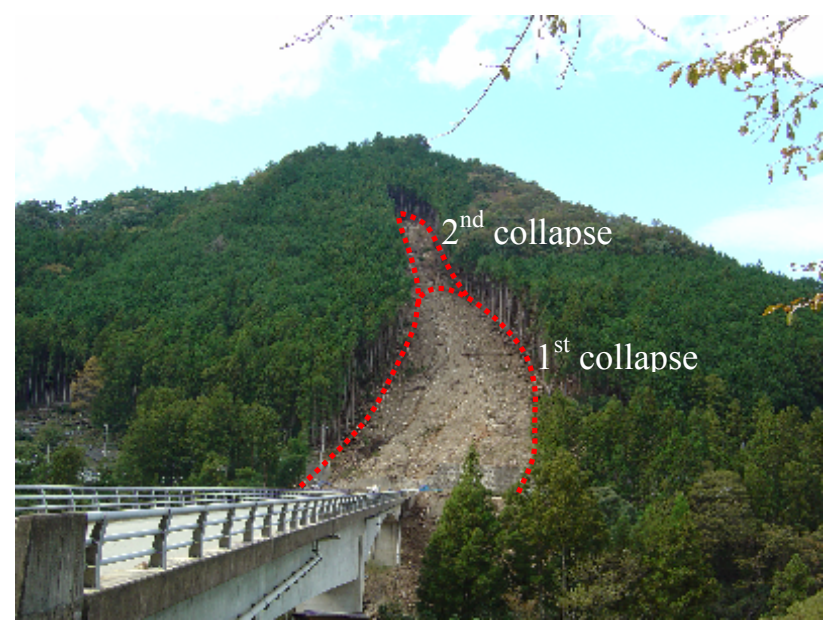

Fig. 7 The multi-phase landslide in the Kotaki area, Miyagawa, Mie Prefecture, on 29 September 2004.

sufficiently, and the preferential flow pathways were not fully represented in the numerical model. Although the modeled preferential flow pathways were quite simplified, simulated soil water infiltration and slope stability differed greatly between the three cases, and the results for Case 3 most resembled the actual landslide occurrence. Therefore, accurate simulations of rainwater infiltration and slope stability must incorporate preferential flow within the soil or bedrock layers.

\section{MULTI-PHASE SLOPE FAILURE}

An investigation of a site after a landslide occurrence cannot reveal whether the slope failed all at once or in multiple stages. It is usually assumed that landslides occur all at once, but some landslides appear to occur through multi-phase slope failure. According to an interview with a resident who witnessed the landslide in the Kotaki area of Miyagawa, Mie Prefecture, on 29 September 2004, the first landslide occurred around 10:15, and approximately $20 \mathrm{~min}$ later the upper part of the first landslide collapsed (Fig. 7). Another typical example is the landslide that occurred in the Minamikouchi area, Taketa, Oita Prefecture, on 6 October 2005. According to an officer from the prefectural government, the first small landslide occurred around 10:30, and the sediment reached a house. One hour later, two residents of the house who had been evacuated for safety, returned home to see the damage. While they were in the house, a second large landslide occurred and completely destroyed the house; the two residents were still listed as missing when we visited the site on 26 October 2005. A similar multi-phase landslide was also observed in 2004 in the Kashu area, Kisaka, Tokushima Prefecture. Therefore, multi-phase landslides are not 
Table 3 Mixing ratio of the material, soil strength and hydraulic conductivity of the soils

\begin{tabular}{ccc}
\hline Case1 & Case2 & Case3 \\
\hline SS3:SS6:PC* & SS3:SS6:PC* & SS3:SS6:PC* \\
80: 0:20 & 100:0:0 & $50: 50: 0$ \\
\hline$c^{\prime}=0.054 \mathrm{tf} / \mathrm{m}^{2}$ & $c^{\prime}=0 \mathrm{tf} / \mathrm{m}^{2}$ & $c^{\prime}=0 \mathrm{tf} / \mathrm{m}^{2}$ \\
$\phi^{\prime}=25$ degree & $\phi^{\prime}=37$ degree & $\phi^{\prime}=37$ degree \\
\hline$K_{s}=0.050$ & $K_{s}=0.567$ & $K_{s}=0.079$ \\
$\mathrm{~cm} / \mathrm{sec}$ & $\mathrm{cm} / \mathrm{sec}$ & $\mathrm{cm} / \mathrm{sec}$
\end{tabular}

*SS3, 6 are the silica sand No. $3\left(D_{50}=1.0 \mathrm{~mm}\right)$ and $6\left(D_{50}=\right.$ $0.2 \mathrm{~mm}$ ), $\mathrm{PC}$ is the pearl clay

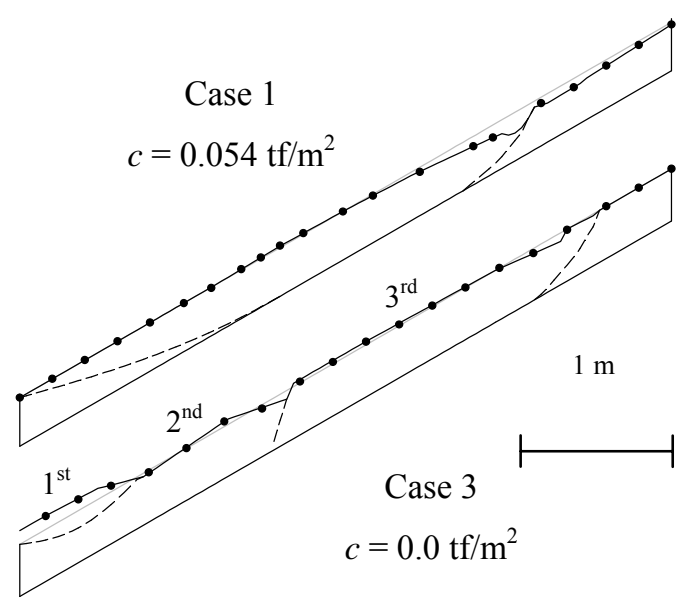

Fig. 8 Observed shapes of slip surfaces for Case 1 and Case 3.

unusual and should be investigated in more detail to elucidate their mechanisms and prevent secondary disasters. The next section presents experimental and simulated results for multi-phase landslides.

\subsection{Experiment}

The experiment was conducted at Ujigawa Open Laboratory, Disaster Prevention Research Institute, Kyoto University. Three different kinds of soils were prepared for the experiment. For all soils, the base material was silica sand No. $3\left(\mathrm{D}_{50}=1.0\right.$ $\mathrm{mm})$. For experimental Case 1, the soil consisted of silica sand No. 3 and pearl clay at a ratio of 80:20. For Case 2, the soil consisted only of silica sand No. 3. For Case 3, the soil consisted of silica sands No. 3 and No. $6\left(D_{50}=0.2 \mathrm{~mm}\right)$ at a ratio of 50:50. Due to the differing mixing materials, each soil had a different internal friction angle $\phi$ and cohesion $c$. Table 3 lists the values of the mixing ratio, $\phi$, and $c$. For all cases, soil was filled in the flume with a length of $5.0 \mathrm{~m}$, a width of $0.2 \mathrm{~m}$, a depth of $0.3 \mathrm{~m}$, and a 30-degree gradient. Artificial rainfall with an intensity of $150 \mathrm{~mm} / \mathrm{hr}$ was applied to the soil surface. During the experiment, water potential at the bottom of the soil layer and surface flow rate were monitored, and slip surfaces of the collapse were recorded using a video camera through a transparent sidewall of the flume.

Landslides occurred in Cases 1 and 3, but not in Case 2 because the soil in Case 2 had such high hydraulic conductivity. A landslide occurred in Case 1 at $15^{\prime} 05^{\prime}$ " from the beginning of rainfall and in Case 3 at 13'13" from the beginning of rainfall. Figure 8 shows the observed shapes of slip surfaces for Cases 1 and 3. A large portion of the slope collapsed at one time in Case 1, but in Case 3 three divided portions of the slope collapsed separately, with an interval of 0.4 seconds. The measured pressure potential indicated that underground water levels differed between Cases 1 and 3. In Case 1, the underground water table almost reached the surface, and the saturated area spread widely through the whole soil layer. Therefore, the entire slope became unstable, resulting in a large slope failure. In Case 3, the underground water table developed near the downslope end, and the saturated area was restricted to the soil layer in the lower part of the slope. Therefore, only the lower part of the slope became unstable, resulting in a small slope failure near the downslope end. Because the upper part of the slope lost support after the first collapse, the second and third collapses occurred one after another. Soil hydraulic properties and soil strength might affect whether a landslide is single or multi-phase. Model simulations were conducted to elucidate how these soil physical properties affect the occurrence of multi-phase landslides; the results are presented in the next section.

\subsection{Model simulation of an actual landslide}

In conventional model simulation of landslides, calculation generally stops once the first landslide occurs $\left(F_{s}\right.$ becomes 1.0). However, simulation of a multi-phase landslide requires that calculations continue after the first landslide has occurred. A new modeling method was developed to simulate multi-phase landslides. When the model has simulated a landslide occurrence, a new problem domain is assumed for the infiltration analysis, removing the soil portion above the calculated slip surface, and calculation continues using the newly assumed soil layer. The newly assumed soil layer is subject to an initial condition of the pressure potential that was calculated just before the former landslide, except for the new downslope end boundary, which was the slip surface of the former landslide. The new downslope end boundary is 
Table 4 Parameters used in numerical simulation of Minamikouchi landslide

\begin{tabular}{cl}
\hline & Soil layer \\
\hline Hydraulic & $K_{s}=0.0048 \mathrm{~cm} / \mathrm{s}$ \\
properties & $\theta_{r}=0.34 \mathrm{~m}^{3} / \mathrm{m}^{3}$ \\
(Measured) & $\theta_{s}=0.57 \mathrm{~m}^{3} / \mathrm{m}^{3}$ \\
& $\psi_{m}=-77 \mathrm{cmH}_{2} \mathrm{O}$ \\
\hline Soil strength & $\sigma=0.73$ \\
(assumed) & $c=0.012 \mathrm{tf} / \mathrm{m}^{2}$ \\
\hline
\end{tabular}
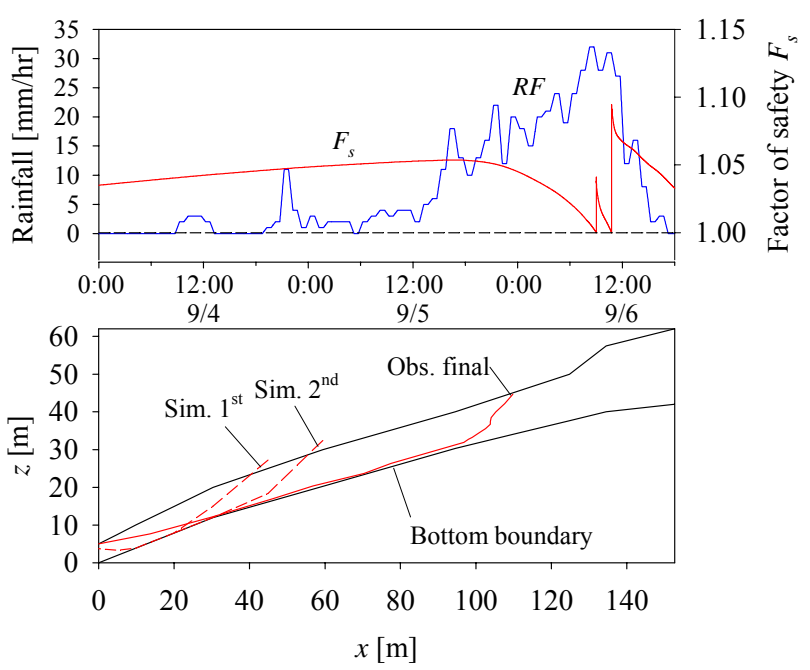

Fig. 9 Simulated results for the multi-phase landslide in Minamikouchi, Taketa, Oita Prefecture.

subject to an initial condition of the pressure potential that was calculated just before the former landslide if it was negative, but a zero pressure potential is given if this value was positive. Table 4 lists the hydraulic properties and soil strength used for the numerical simulation of the slope in the Minamikouchi area, Taketa, Oita Prefecture.

Figure 9 shows the results of the slope simulation for the Minamikouchi area, where a multi-phase landslide occurred on 6 September, 2005. At 9:01, the factor of safety was calculated at 1.0, and the first landslide occurred. After the unstable part of the slope was removed, the factor of safety increased, and calculation continued; the second landslide occurred at 10:46. The timing of the simulated multi-phase landslide matched well with the actual landslide, but the final shape of the simulated landslide scar was smaller than the observed shape due to the simplest re-formation of the soil layer and pressure potential conditions after
Table 5 Parameters used in numerical analysis for landslide size and timing depending on soil physical properties

\begin{tabular}{clc}
\hline & \multicolumn{1}{c}{ Case 1 } & Case 3 \\
\hline & $K_{s}=0.050 \mathrm{~cm} / \mathrm{s}$ & $K_{s}=0.079 \mathrm{~cm} / \mathrm{s}$ \\
Hydraulic & $\theta_{r}=0.138 \mathrm{~m}^{3} / \mathrm{m}^{3}$ & $\theta_{r}=0.046 \mathrm{~m}^{3} / \mathrm{m}^{3}$ \\
properties & $\theta_{s}=0.481 \mathrm{~m}^{3} / \mathrm{m}^{3}$ & $\theta_{s}=0.365 \mathrm{~m}^{3} / \mathrm{m}^{3}$ \\
(Measured) & $\psi_{m}=-5.65 \mathrm{cmH}_{2} \mathrm{O}$ & $\psi_{m}=-15.4 \mathrm{cmH}_{2} \mathrm{O}$ \\
& $\sigma=1.09$ & $\sigma=0.580$ \\
\hline \multirow{2}{*}{ Soil strength } & $15<\phi<40 \mathrm{degree}, \Delta \phi=1$ degree \\
& $0.00<c<0.15 \mathrm{tf} / \mathrm{m}^{2}, \Delta c=0.01 \mathrm{tf} / \mathrm{m}^{2}$ \\
\hline
\end{tabular}

the earlier landslide. More precise results will require improving the simulation methodology with regard to the re-formation of surface topography and the distribution of water pressure after the removal of the earlier landslide.

4.3 Numerical analysis of landslide size and timing based on soil physical properties

The experiment discussed in the previous subsection revealed that the type of landslide (single or multi-phase) depended on soil physical properties. The corresponding model simulation also produced differing landslide results due to the various soil physical properties. To determine how each physical property affects multi-phase landslide occurrence, simulations were conducted using a hypothetical slope the same size as the experimental slope, applying various values for internal friction angle $\phi$, cohesion $c$, and hydraulic conductivity $K_{s}$. Table 5 lists the parameters used in the numerical simulation. Values for the simulated slope, soil hydraulic properties, and rainfall conditions were identical to those used in the experiment discussed in the previous subsection. Figures $\mathbf{1 0}$ and $\mathbf{1 1}$ show how soil strength affects the timing and size of the first landslide; the red triangles represent areas where the slope collapsed during the initial simulation stages, and the blue triangles represent areas where the slope did not collapse at the equilibrium state. The circles and values in parentheses represent the experimental results. Figure 10 reveals that the timing of landslide occurrence increased as both the internal friction angle $\phi$ and cohesion $c$ increased. These results appear to reflect reality; comparison of the simulated and experimental results showed that the actual landslides occurred slightly earlier than the simulated landslides in Cases 1 and 3. Figure 11 reveals that landslide size tends to increase as soil cohesion $c$ increases and internal friction angle $\phi$ decreases; this 

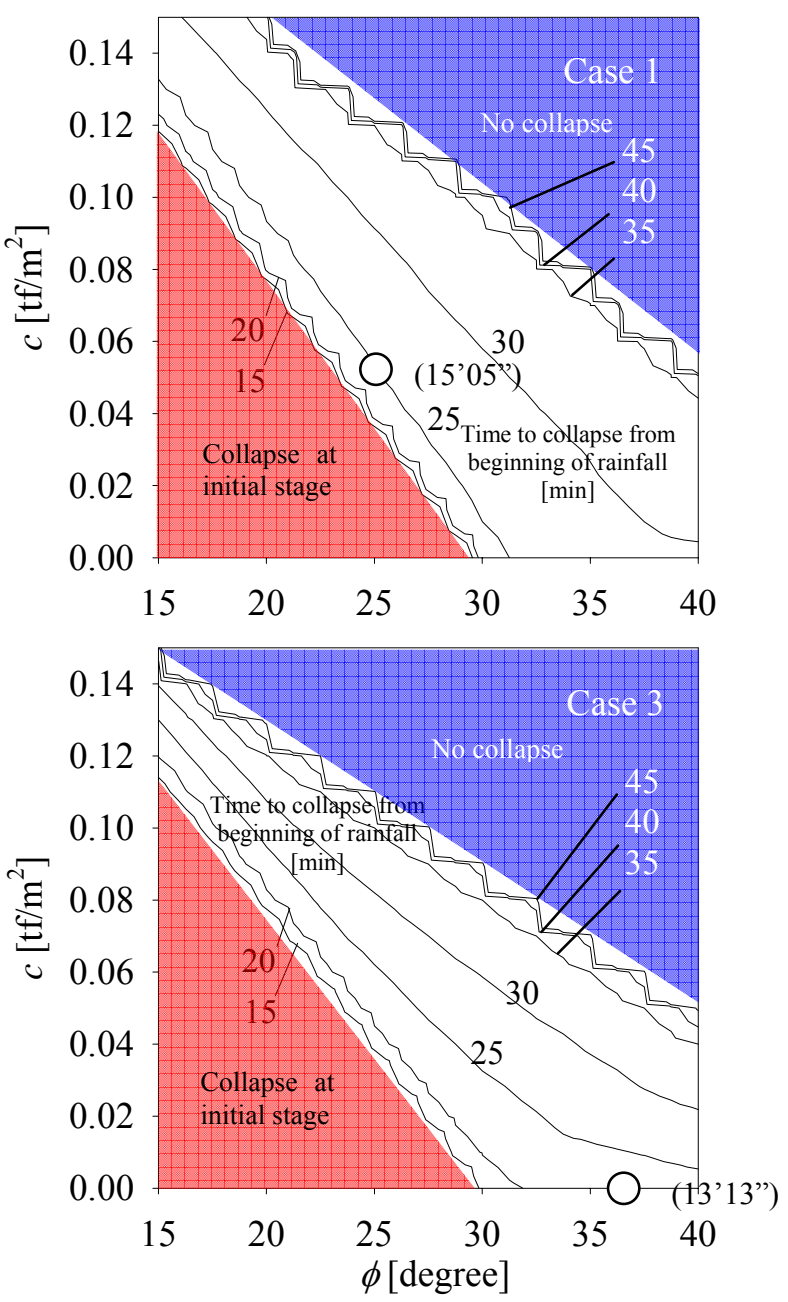

Fig. 10 The effect of soil strength on simulated landslide occurrence time (circles represent experimental results).

held true for Cases 1 and 3. This tendency indicates that if the soil has large $c$ values and small $\phi$ values, a large part of the slope will collapse at one time; in contrast, if the soil has small $c$ values and large $\phi$ values, a multi-phase landslide is more likely. The simulated and experimental results did not match perfectly with regard to the actual size of the first collapse, but simulations were able to represent the differing tendencies between Cases 1 and 3 very well. The results revealed similar tendencies between Cases 1 and 3, but the details differed. Therefore, the timing and size of the first landslide are also affected by hydraulic properties, slope shape, and rainfall patterns.

\section{EFFECTS OF CHARACTERISTICS}

A deep-seated landslide occurred in the Senokuchi area, Taketa, Oita Prefecture, after more
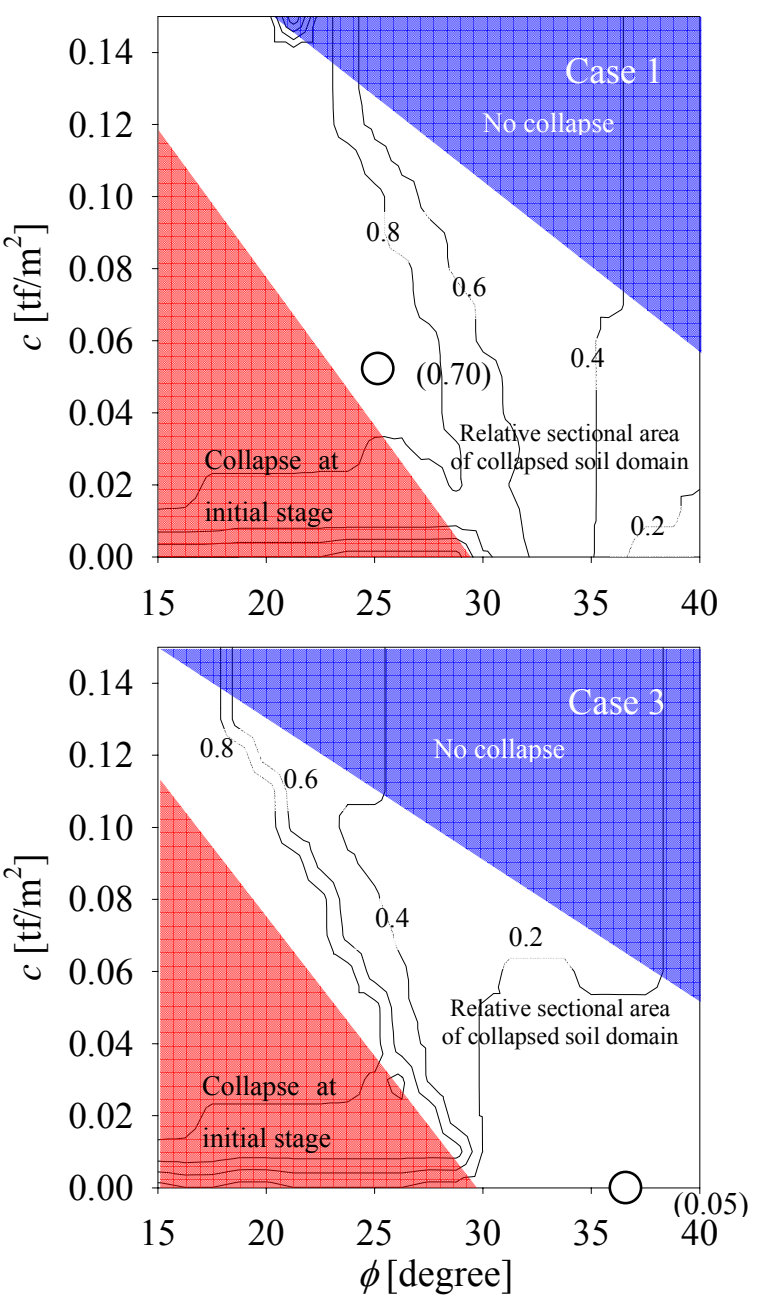

Fig. 11 The effect of soil strength on a relative sectional area of collapsed soil domain obtained by the simulation (circles represent experimental results).

than $500 \mathrm{~mm}$ total precipitation from typhoon 0514 on 6 September 2005 (Fig. 12). The maximum rainfall intensity was not particularly great (about 30 $\mathrm{mm} / \mathrm{hr}$ ), but rainfall duration was more than 48 hours antecedent to the landslide occurrence. It is well known that deep-seated landslides are usually caused by a rainfall event with large total precipitation and long duration. The Senokuchi landslide exemplified this relationship.

Rainwater infiltration and slope stability analyses were conducted to elucidate how rainfall characteristics such as intensity and duration affect landslides. These analyses applied actual measured rainfall and three differing hypothetical rainfall values to the slope in the Senokuchi area. Figure 13 shows four rainfall events that were applied in the simulation. Case 1 is the actual measured rainfall; Case 2 is a hypothetical rainfall with double the intensity and half the duration of Case 1; Case 3 is a hypothetical rainfall with four times the intensity and 


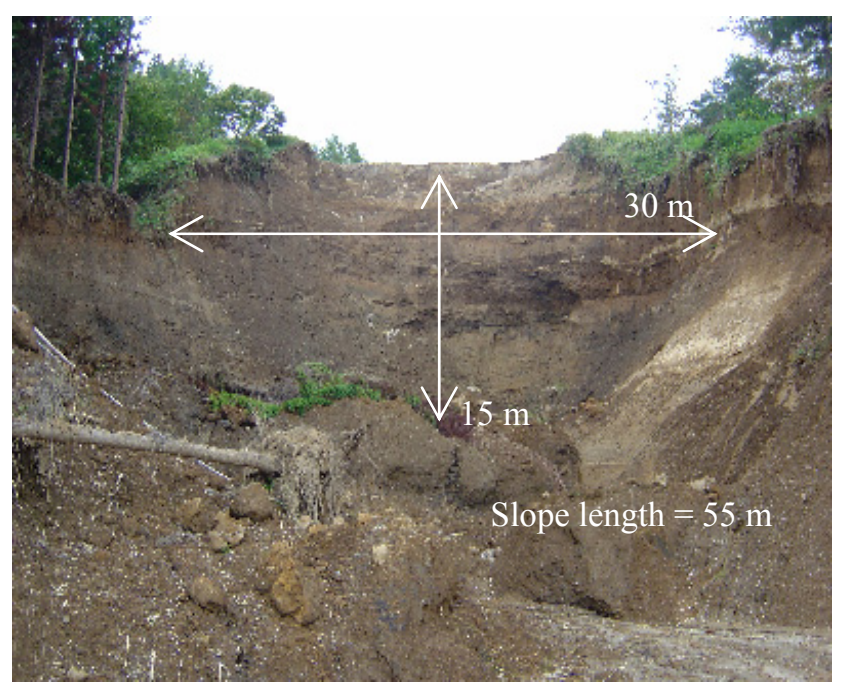

Fig. 12 A deep-seated landslide that occurred in the Senokuchi area, Taketa, Oita Prefecture, on 6 September 2005.

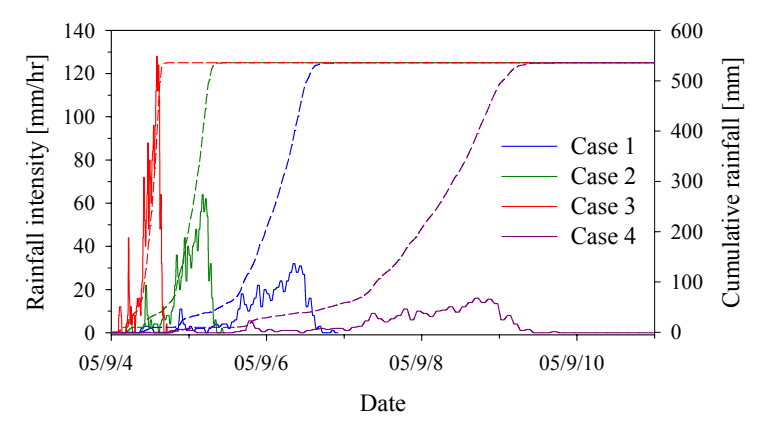

Fig. 13 Measured rainfall (Case 1) and three differing sets of hypothetic rainfall data (Cases 2, 3 and 4) that were used in the simulation.

one-quarter the duration of Case 1; and Case 4 is a hypothetical rainfall with half the intensity and twice the duration of Case 1. Thus, while each case has a different intensity and duration, they all have identical total precipitation. Table 6 lists the parameters used in the numerical simulations.

Figure 14 shows the results for the Case 1 simulation; the upper figure presents changes in rainfall intensity and factor of safety $\left(F_{s}\right)$, and the lower figure illustrates the distribution of the pressure potential and the shape of the slip surface when calculated $F_{s}$ was zero. The estimated time of landslide occurrence was 13:55, 6 September, about three hours after the time of peak rainfall; this was very similar to the actual time of landslide occurrence (around 14:00). The slip surface was calculated as if it cut off the low pressure potential area from the soil layer. The calculated and observed shapes, length, and depth of the slip surface were very similar. These temporal and spatial results suggest that the model simulated the landslide quite accurately. However, the slope stability analysis was two dimensional and thus unable to incorporate the
Table 6 Parameters used in numerical simulations of

Senokuchi landslide affected by rainfall patterns

\begin{tabular}{|c|c|c|c|}
\hline & Surface & Middle & Lower \\
\hline \multicolumn{4}{|c|}{ Hydraulic properties (Measured) } \\
\hline$K_{s}[\mathrm{~cm} / \mathrm{s}]$ & $2.42 \times 10^{-2}$ & $3.32 \times 10^{-3}$ & $5.69 \times 10^{-4}$ \\
\hline$\theta_{r}\left[\mathrm{~m}^{3} / \mathrm{m}^{3}\right]$ & 0.477 & 0.441 & 0.577 \\
\hline$\theta_{s}\left[\mathrm{~m}^{3} / \mathrm{m}^{3}\right]$ & 0.646 & 0.595 & 0.682 \\
\hline$\psi_{m}[\mathrm{~cm}]$ & -792 & -595 & -797 \\
\hline$\sigma[-]$ & 0.875 & 1.36 & 1.02 \\
\hline \multicolumn{4}{|c|}{ Soil strength (assumed) } \\
\hline$c\left[\mathrm{tf} / \mathrm{m}^{2}\right]$ & 2.0 & 2.0 & 2.0 \\
\hline$\phi$ [degree $]$ & 17 & 17 & 17 \\
\hline
\end{tabular}

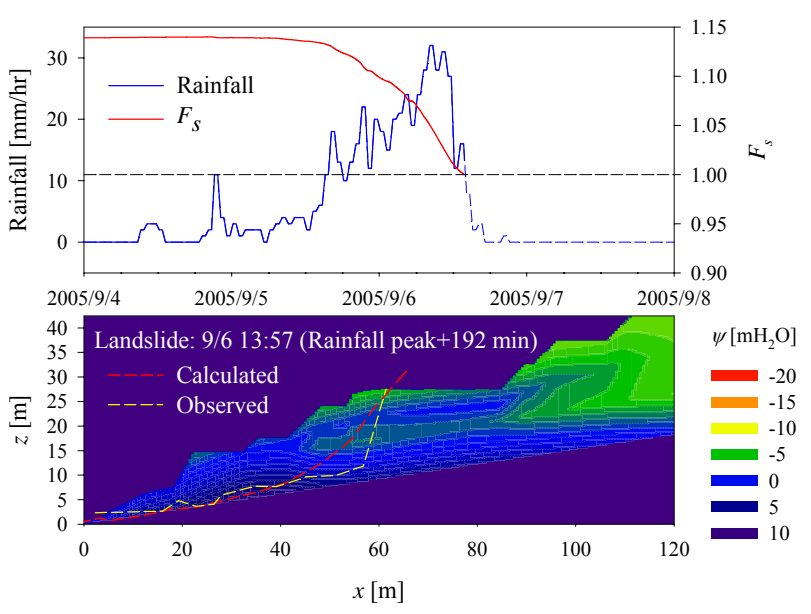

Fig. 14 (Upper) Changes in factor of safety $\left(F_{s}\right)$ and comparison between the observed and simulated slip surface drawn on the pressure potential distribution within the soil layer (lower), calculated for Case 1.

three-dimensional shapes of the slip surface and bedrock topography. Therefore, the simulated landslide was not a reproduction of the actual landslide, but the method by which it was obtained could be used to investigate the effect of rainfall patterns on landslide characteristics.

Model simulations were also conducted for Cases 2, 3, and 4. Figure 15 presents the results along with the results for Case 1. The upper figure shows changes in rainfall intensity and $F_{s}$, and the lower figure shows the calculated shape of the slip surface for each case. In each case, $F_{s}$ decreased as rainfall increased, but its sensitivity to rainfall varied depending on the rainfall pattern (i.e., $F_{s}$ decreased more rapidly when rainfall had a higher intensity and 


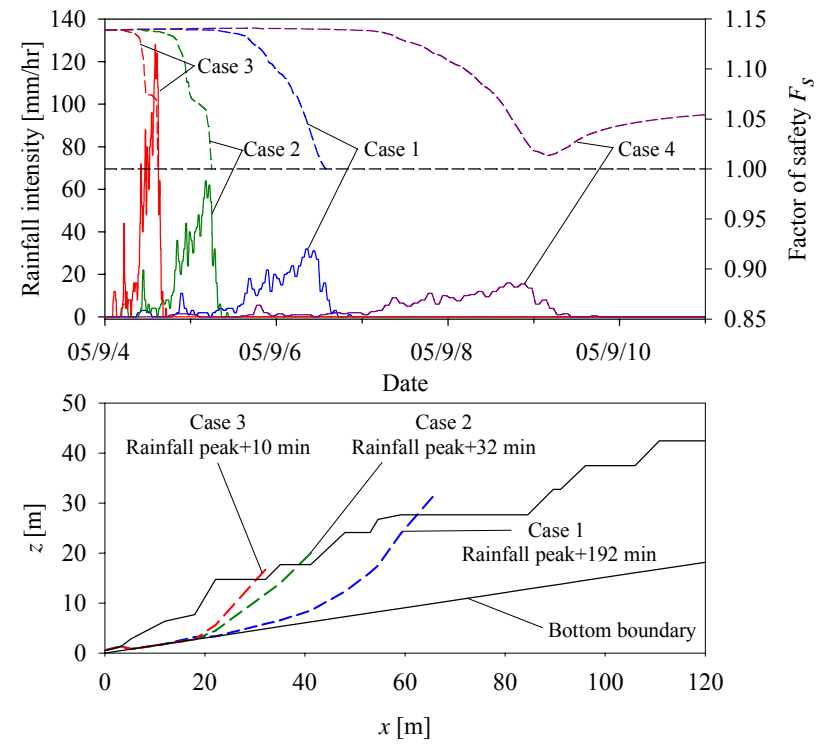

Fig. 15 (Upper) Changes in rainfall intensity and simulated factors of safety $\left(F_{s}\right)$ and calculated shapes of the slip surface (lower) for each rainfall pattern.

shorter duration). Delays from rainfall peak to landslide occurrence were 192, 32, and $10 \mathrm{~min}$ for Cases 1, 2, and 3, respectively. With regard to the shape of the slip surface (see Fig. 15, lower figure), the size of the landslide increased with longer rainfall duration and lower rainfall intensity. These temporal and spatial landslide tendencies depending on the rainfall pattern matched the empirical results well. No landslide occurred in the simulation with the longest rainfall duration and lowest rainfall intensity (Case 4). Therefore, the threshold of rainfall intensity that can cause a landslide may vary for each slope depending on the topography and hydraulic properties of the soil layer.

\section{CONCLUSIONS}

In this study, we investigated four landslide disaster sites and conducted various numerical simulations. These investigations and simulations revealed several important factors for clarifying the mechanism of landslide occurrence and mitigating landslide disasters:

1) The field investigation revealed that preferential flow pathways though fractures in weathered bedrock triggered a deep-seated landslide in Minamata, and a numerical simulation that incorporated preferential flow confirmed this mechanism of landslide occurrence.

2) More accurate prediction of landslide occurrence requires incorporating subsurface geomorphology, including preferential flow pathways.
3) Multi-phase landslides were observed at several sites, and it was confirmed that this phenomenon is not uncommon. Numerical simulations revealed that the size of the first landslide, which is a criterion for multi-phase landslide occurrence, depends on soil physical properties including internal friction angle and soil cohesion.

4) It was confirmed that even with identical total precipitation on an identical slope, differing rainfall patters affect landslide scale and time of occurrence. The relationship between simulated landslide and rainfall characteristics matched empirical results well.

To elucidate landslide mechanisms and mitigate landslide disasters, methods of landslide prediction must be improved by incorporating complicated factors such as subsurface geomorphology, multi-phase landslide occurrence, and rainfall characteristics.

ACKNOWLEDGMENTS: We thank Dr. Roy C. Sidle of Appalachian State University for his helpful comments and suggestions. We also thank Mr. Toshihiko Miyazaki and Mr. Yuichiro Hayashi, who were Master's students at Kyoto University, for their generous efforts in conducting experiments and simulations.

\section{REFERENCES}

Dietrich, W.E., Dunne, T. (1978): Sediment budget for a small catchment in mountainous terrain, Z. Geomorph. N. F., Suppl. Bd. 29, pp. 191-206

Hack, J.T., Goodlett J.C. (1960): Geomorphology and forest ecology of a mountain region in the central Appalachians, U.S. Geol. Surv. Prof. Pap., 374, pp. 1-66

Harp, E.L., Wells, W.G. II, Sarmiento, J.G. (1990): Pore pressure response during failure in soils, Geol. Soc. Am. Bull., 102(4), pp. $428-438$

Istok, J. (1989): Groundwater Modeling by the Finite Element Method, American Geophysical Union, Washington DC, p. 495

Iverson, R.M. (2000): Landslide triggered by rain infiltration, Water Resources Research, 36(7), pp. 1897-1910

Keefer, D.K., Wilson, R.C., Mark, R.K., Brabb, E.E., Brown, W.M. III, Ellen, S.D., Harp, E.L., Wieczorek, G.F., Alger, C.S., Zatkin, R.S. (1987): Real-time landslide warning during heavy rainfall, Science, 238, pp. 921-925

Kitahara, H. (1989): Characteristics of pipe flow in a subsurface soil layer on a gentle slope (II) Hydraulic properties of pipes, Journal of the Japanese Forestry Society, 71, pp. 317-322 (In Japanese with English summary)

Kosugi, K. (1996): Lognormal distribution model for unsaturated soil hydraulic properties, Water Resources Research, 32, pp. 2697-2703.

Kubota, T., Nakamura, H. (1991): Landslide susceptibility estimation by critical slip surface analysis combined with reliable analysis, Journal of Japan Landslide Society, 27(4), 
pp. 18-25 (In Japanese with English abstract)

Montgomery, D.R., Dietrich, W.E., Torres R., Anderson, S.P., Heffner, J.T., Loague, K. (1997): Hydrologic response of a steep, unchanneled valley to natural and applied rainfall, Water Resources Research, 33(1), pp. 91-109

Pierson, T.C. (1983): Soil pipes and slope stability, Quarterly Journal of Engineering Geology, 16, pp. 1-11.

Sidle, R.C. Chigira, M. (2004): Landslides and debris flows strike Kyushu, Japan, EOS transactions AGU, 85 (15), pp. $145,151$.

Sidle, R.C., Swanston, D.N. (1982): Analysis of a small debris slide in coastal Alaska, Can. Geotech. J., 19, pp. 167-174

Tsutsumi, D., Fujita, M., Sidle, R.C. (2005c): Numerical model of water flow in weathered bedrock and its effect on slope stability, Proceedings of International Symposium on Fluvial and Coastal Disasters , CDROM

Tsutsumi, D., Miyazaki, T., Fujita, M., Sidle, R.C. (2005b): Numerical model relation to pipeflow and its assessment by flume experiments, Journal of the Japan Society of Erosion Control Engineering, Vol. 58 (1), pp. 20-30 (In Japanese with English abstract)

Tsutsumi, D., Sidle, R.C., Fujita, M., Mizuyama, T. (2004): Numerical experiments to assess the influence of pipeflow on slope stability, Annual Journal of Hydraulic Engineering,
Vol. 48, pp. 337-342 (In Japanese with English abstract)

Tsutsumi, D., Sidle, R.C., Kosugi, K. (2005a): Development of a simple lateral preferential flow model with steady-state application in hillslope soils. Water Resources Research , Vol. 41, W12420 , doi:10.1029/2004WR003877

Uchida, T., Kosugi, K., Mizuyama, T. (2001): Effect of pipeflow on hydrological process and its relation to landslide: a review of pipeflow studies in forested headwater catchments, Hydrol. Process., 15, pp. 2151-2174

Uchida, T., Kosugi, K., Ohte, N., Mizuyama, T (1995): An experimental study on influence of soil pipe for groundwater table, Transactions of the Japanese Forestry Society, 106, pp. 505-508 (In Japanese)

Vieira, B.C., Fernandes, N.F. (2004): Landslides in Rio de Janeiro: the role played by variations in soil hydraulic conductivity, Hydrol. Process., 18, pp. 791-805

Yamagami, T., Ueta, Y. (1988) Search for critical slip lines in finite element stress fields by dynamic programming, Proc. 6th International Conference on Numerical Methods in Geomechanics. Innsbruck, Austria, pp. 1335-1339

Zienkiewicz, O.C. (1971): The Finite Element method in Engineering Science, McGraw-Hill, Berkshire, England 